\title{
Non-muscle myosin II is an independent predictor of overall survival for cystectomy candidates with early-stage bladder cancer
}

\author{
DAN XIONG ${ }^{1,2 *}$, YUN-LIN YE ${ }^{1-3^{*}}$, MING-KUN CHEN ${ }^{1,2}$, ZI-KE QIN $^{1,2}$, MAN-ZHI LI $^{1,2}$, \\ HUA ZHANG $^{1,2}$, LI-HUA XU ${ }^{1,2}$, ZHEN-ZHOU XU ${ }^{1,2}$ and MU-SHENG ZENG ${ }^{1,2}$ \\ ${ }^{1}$ State Key Laboratory of Oncology in South China; ${ }^{2}$ Department of Experimental Research, \\ Sun Yat-sen University Cancer Center, Guangzhou 510060; ${ }^{3}$ Department of Urology, \\ The First Affiliated Hospital, Sun Yat-sen University, Guangzhou, Guangdong 510080, P.R. China
}

Received April 4, 2012; Accepted July 2, 2012

DOI: 10.3892/or.2012.1965

\begin{abstract}
Non-muscle myosin heavy chain IIA (NMHC IIA) plays a significant role in tumor progression and metastasis. The aim of this study was to explore the relationship between the expression levels of NMHC IIA and the characteristics, prognosis of patients who were cystectomy candidates with early-stage bladder cancer. Real-time PCR was used to examine the expression of NMHC IIA mRNA in 16 paired bladder cancer and the adjacent normal tissues. The expression of NMHC IIA protein in 167 specimens of bladder cancer was determined by immunohistochemistry assay. Statistical analyses were performed to evaluate the association between the expression of NMHC IIA, and clinicopathological features and prognosis. Compared with adjacent normal bladder tissues, upregulated expression of NMHC IIA mRNA was observed in $81.3 \%$ of bladder cancer tissues $(\mathrm{P}=0.011)$. Moreover, the higher levels of NMHC IIA expression were positively correlated with the histopathological classification $(\mathrm{P}=0.021)$, lymph node metastasis $(\mathrm{P}=0.047)$ and cancer-related mortality $(\mathrm{P}=0.030)$. The 5-year survival rate of patients with higher NMHC IIA expression was significantly lower than that of patients with lower NMHC IIA expression ( $\mathrm{P}=0.004)$. Furthermore, in multivariate analysis by Cox regression model, high NMHC IIA expression was confirmed to be an independent molecular marker $(\mathrm{P}=0.047)$, while grade $(\mathrm{P}=0.020)$ and clinical $\mathrm{T}$ stage $(\mathrm{P}=0.049)$ were also significant prognostic factors. Expression of NMHC IIA mRNA was higher in bladder cancer compared
\end{abstract}

Correspondence to: Dr Mu-Sheng Zeng, Sun Yat-sen University Cancer Center, 651 Dongfeng Road East, Guangzhou 510060, P.R. China

E-mail: zengmsh@mail.sysu.edu.cn

*Contributed equally

Key words: non-muscle myosin heavy chain IIA, bladder cancer, prognosis, cystectomy candidate to the adjacent normal tissues. The detection of NMHC IIA protein expression is potentially useful in prognostic evaluation of cystectomy candidates with early-stage bladder cancer.

\section{Introduction}

Bladder cancer is the fourth most common cancer and is the ninth leading cause of cancer-related mortality among men in the United States (1); it is also the most common urologic cancer in China (2). An estimated 70,530 new cases were diagnosed and 14,680 people succumbed to bladder cancer in the United States in 2010 (3). Although the majority of patients present with superficial bladder tumors, $50-70 \%$ will recur and $10-30 \%$ will progress to muscle-invasive disease (1). Although organ-confined muscle-invasive bladder cancer was subjected to radical cystectomy according to the NCCN guidelines, bladder-sparing tri-modality is an alternative approach (4). Bladder cancer has a tendency to recur, and with recurrence a few number of cases progress, making the early detection of high-risk patients urgent (1). Clinical stage and histological grade are significant predictors of outcome (5). Tumor number and lymphovascular invasion are also reported to be associated with recurrence after surgery (6). However, few biomarkers were considered as prognostic factors in cystectomy candidates with organ-confined bladder cancer.

Non-muscle myosin II A (NM IIA), which belongs to the myosin II subfamily, is an actin-binding protein and is regulated by the phosphorylation of its heavy and light chains (7). NMHC IIA is a subunit of NM IIA which is central to the control of cell adhesion, cell migration and tissue architecture $(7,8)$. MYH9 gene localized to chromosome 22 q11.2 and encoded NMHC IIA (9), whose mutations are responsible for a complex disorder named MYH9-related disease, are characterized by an association of different phenotypic features (10). Although NM IIA has a basic role in processes that require cellular reshaping and movement, such as cell adhesion and cell migration $(7,11)$, only a few studies have evaluated its role in cancer tissues. Its expression has been accounted as a negative prognostic indicator in stage I lung adenocarcinoma (12). Another study of non-small cell lung cancer indicated that 
Table I. Clinical characteristics of cystectomy candidates with early-stage bladder cancer.

\begin{tabular}{|c|c|c|c|}
\hline Group & $\begin{array}{l}\text { No. of patients treated with } \\
\text { radical cystectomy }(\%)\end{array}$ & $\begin{array}{l}\text { No. of patients treated with } \\
\text { bladder-sparing approach }(\%)\end{array}$ & P-value \\
\hline \multicolumn{4}{|c|}{ Age (years) } \\
\hline$\leq 60$ & $50(50)$ & $50(50)$ & \multirow[t]{2}{*}{0.394} \\
\hline$>60$ & $38(57)$ & $29(43)$ & \\
\hline \multicolumn{4}{|l|}{ Gender } \\
\hline Male & $86(57)$ & $65(43)$ & \multirow[t]{2}{*}{0.001} \\
\hline Female & $2(13)$ & $14(87)$ & \\
\hline \multicolumn{4}{|l|}{ Size $(\mathrm{cm})$} \\
\hline$>3$ & $36(35)$ & $67(65)$ & \multirow[t]{2}{*}{0.000} \\
\hline$\leq 3$ & $52(81)$ & $12(19)$ & \\
\hline \multicolumn{4}{|l|}{ Number } \\
\hline$>3$ & $69(57)$ & $52(43)$ & \multirow[t]{2}{*}{0.069} \\
\hline$\leq 3$ & $19(41)$ & $27(59)$ & \\
\hline \multicolumn{4}{|c|}{ Clinical stage } \\
\hline Tis,T1 & $24(45)$ & $29(55)$ & \multirow[t]{2}{*}{0.191} \\
\hline $\mathrm{T} 2$ & $64(56)$ & $50(44)$ & \\
\hline \multicolumn{4}{|l|}{ Grade } \\
\hline $\mathrm{G} 1, \mathrm{G} 2$ & $33(54)$ & $28(46)$ & \multirow[t]{2}{*}{0.783} \\
\hline G3 & $55(52)$ & $51(48)$ & \\
\hline
\end{tabular}

overactivation of myosin II could be a factor contributing to metastasis (13). Overexpression of myosin IIA may promote the progression and poor prognosis of esophageal squamous cancer, and this effect may be related to increased cancer cell migration (14). However, there is currently no report on the relationship between myosin IIA expression and bladder cancer.

The purpose of the present study was to investigate the expression level of NMHC IIA in bladder cancer and its clinicopathological and prognostic significance. In this study, real-time PCR and immunohistochemistry assay were performed to examine mRNA and protein expression in a cohort of early-stage bladder cancer cystectomy candidates.

\section{Materials and methods}

Patients and tissue specimens. For real-time PCR, 16 paired bladder cancer and adjacent normal bladder tissues were collected from patients who underwent surgery between March 2010 and June 2010. In addition, 167 paraffinembedded specimens of bladder cancer from 88 patients treated with radical cystectomy and 79 patients of bladdersparing treatment were collected between January 2003 and December 2009 for immunohistochemical assay. Patients with non-urothelial tumor ingredients, imaging of hydronephrosis, metastasis and T3b-T4 disease were excluded from the radical cystectomy group. Clinical staging was carried out according to the American Joint Committee on Cancer (AJCC) TNM Staging System (7th edition, 2010) and histologic grade was according to WHO 1973. The clinicopathological characteristics of cystectomy candidates with early-stage bladder cancer are summarized in Table I. Consent from the patients and approval from the Sun Yat-sen University Cancer Center institute research ethics committee were obtained before using these clinical materials.

RNA extraction and real-time PCR analysis. Total RNA was isolated from 16 pairs of bladder cancer tissues and their adjacent normal bladder tissues using TRIzol reagent (Invitrogen, Carlsbad, CA, USA). RNA was reverse-transcribed performing SuperScript First Strand cDNA System (Invitrogen). The first strand cDNA products were then amplified with GAPDHspecific (F: 5'-CTCCTCCTGTTCGACAGTCAGC-3' and R: 5'-CCCAATACGACCAAATCCGTT-3') and NMHC IIA-specific (F: 5'-CCATCACAGACACCGCCTACAG-3' and R: 5'-CTTCTTGGTGTTCTCCGTCTTGC-3') primers by real-time PCR and data collection were performed on the ABI Prism 7900HT system.

Immunohistochemistry analysis. Immunohistochemistry was performed as a modification of the method previously described (15). Paraffin-embedded specimens were cut into $4-\mu \mathrm{m}$ sections and baked at $65^{\circ} \mathrm{C}$ for $30 \mathrm{~min}$. Following deparaffinization and hydration, endogenous peroxidase was blocked using blocking buffer (3\% hydrogen peroxide) and antigen retrieval was implemented in a pressure sterilizer. After the sections were incubated with $1 \%$ bovine serum albumin for $30 \mathrm{~min}$ at room temperature, the rabbit polyclonal anti-NMHC-IIA antibody (Abcam, Cambridge, UK) (1:2000) was added and set overnight in a wetting case at $4^{\circ} \mathrm{C}$. After washing, the biotinylated anti-rabbit secondary antibody was added, followed by streptavidin-horseradish peroxidase 


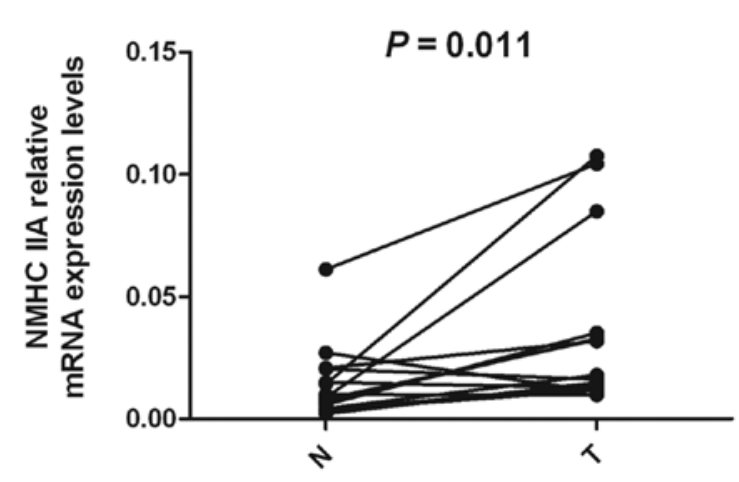

Figure 1. Expression of NMHC IIA mRNA in paired bladder cancer and the adjacent normal tissues by real-time PCR analysis. T, 16 paired bladder cancer tissues; $\mathrm{N}$, the adjacent normal bladder tissues. GAPDH was used as the internal control.

complex. The sections were counterstained with hematoxylin before mounting and evaluating. Negative controls were performed using the non-immune rabbit IgG of the same isotype instead of NMHC-IIA antibody.

Statistical analysis. All statistical analyses were carried out with the SPSS 16.0 statistical software package. In the real-time PCR, Student's t-test was used to analyze mRNA expression between bladder cancer and adjacent normal tissues. The $\chi^{2}$ test for proportion was used to analyze the relationship between NMHC IIA protein expression and clinicopathological characteristics. Cancer-specific survival rates, recurrence-free survival rates and overall survival rates were calculated using the Kaplan-Meier method and compared by the log-rank test. The clinical characteristics of patients treated with the bladder-sparing approach and radical cystectomy were compared by the $\chi^{2}$ test and the rank sum test. Prognostic factors were evaluated using the cox regression method. $\mathrm{P}<0.05$ was considered to indicate statistically significant differences.

\section{Results}

Detection of NMHC IIA mRNA expression in paired bladder tissues. To investigate the status of transcriptional expression of NMHC IIA in bladder cancer, real-time PCR was performed in 16 pairs of bladder cancer and adjacent normal bladder specimens, respectively. In the real-time PCR analysis, a total of 13 of $16(81.3 \%)$ bladder cancer tissues showed upregulated NMHC IIA expression, when compared with their adjacent normal bladder tissues. Expression of mRNA was found to be higher in tumor tissues than in the paired adjacent normal tissues $(\mathrm{P}=0.011)$ (Fig. 1). The relative expression levels were determined as a ratio between NMHC IIA and the reference gene (GAPDH) for variation in the quantity of mRNA. The ratios (bladder cancer/normal tissue) were 4.0, 1.5, 7.3, 2.1, 7.0, 4.5, 3.0, 5.9, 9.6, 3.1, 1.7, 4.2 and 3.3, respectively. This result was in line with the NMHC IIA expression data in two microarray expression profiling reports as deposited in the Oncomine database $(16,17)$. Oncomine expression analysis showed consistent NMHC IIA upregulation in human bladder cancer compared with normal bladder tissues (Fig. 2).
Table II. Correlation between the expression of NMHC IIA protein and clinicopathological factors in cystectomy candidates with early-stage bladder cancer.

\begin{tabular}{|c|c|c|c|c|}
\hline \multirow[b]{2}{*}{ Characteristics } & \multirow[b]{2}{*}{$\mathrm{N}$} & \multicolumn{2}{|c|}{ NMHC IIA expression } & \multirow[b]{2}{*}{ P-value } \\
\hline & & Low $(\%)$ & High $(\%)$ & \\
\hline \multicolumn{5}{|l|}{ Gender } \\
\hline Male & 151 & $52(34)$ & 99 (66) & 0.807 \\
\hline Female & 16 & $6(38)$ & $10 \quad(62)$ & \\
\hline \multicolumn{5}{|l|}{ Age (years) } \\
\hline$<60$ & 100 & $35(35)$ & $65(65)$ & 0.929 \\
\hline$\geq 60$ & 67 & $23(34)$ & $44(66)$ & \\
\hline \multicolumn{5}{|l|}{ Tumor no. } \\
\hline$\leq 3$ & 121 & $43(36)$ & $78 \quad(64)$ & 0.723 \\
\hline$>3$ & 46 & $15(33)$ & $31 \quad(67)$ & \\
\hline \multicolumn{5}{|l|}{ Clinical stage } \\
\hline Tis,T1 & 53 & $23(43)$ & $30 \quad(57)$ & 0.109 \\
\hline $\mathrm{T} 2$ & 114 & $35(31)$ & $79(69)$ & \\
\hline \multicolumn{5}{|l|}{ Grade } \\
\hline $\mathrm{G} 1, \mathrm{G} 2$ & 61 & $28(46)$ & $33 \quad(54)$ & 0.021 \\
\hline G3 & 106 & $30(28)$ & $76 \quad(72)$ & \\
\hline \multicolumn{5}{|l|}{ Tumor size $(\mathrm{cm})$} \\
\hline$\leq 3$ & 103 & $41(40)$ & $62(60)$ & 0.081 \\
\hline$>3$ & 64 & $17(27)$ & $47 \quad(73)$ & \\
\hline \multicolumn{5}{|l|}{ Group } \\
\hline $\mathrm{BS}$ & 79 & $24(30)$ & $55(70)$ & 0.263 \\
\hline $\mathrm{RC}$ & 88 & $34(39)$ & $54 \quad(61)$ & \\
\hline \multicolumn{5}{|l|}{ Lymph node } \\
\hline NO & 160 & $58(36)$ & 102 (64) & 0.047 \\
\hline $\mathrm{N} 1, \mathrm{~N} 2$ & 7 & $0 \quad(0)$ & $7(100)$ & \\
\hline
\end{tabular}

BS, bladder-sparing; RC, radical cystectomy.

Expression of NMHC IIA protein in paraffin-embedded bladder cancer tissues. Expression and subcellular location of NMHC IIA protein were investigated by immunohistochemistry of 167 paraffin-embedded, archival bladder cancer tissues. Representative staining of NMHC IIA in the cancer is shown in Fig. 3. The NMHC IIA protein staining was localized mainly in the cytoplasm of all tumor tissues and on the cell membrane of some tumor tissues (Fig. 3). Samples with $>50 \%$ of the cells showing immunohistochemical reactivity for NMHC IIA were considered as positive according to the criteria by Maeda et al (12). Positive expression was further subdivided into weakly positive (Fig. 3B), median positive (Fig. 3C) and strongly positive (Fig. 3D) based on staining intensity. The negative NMHC IIA staining is shown in Fig. 3A. The low expression of NMHC IIA included weakly positive and negative staining. The median positive and strongly positive staining was considered as high expression of NMHC IIA.

Relationship between NMHC IIA expression and clinicopathological characteristics. The relationship between the expression of NMHC IIA protein and clinical character- 

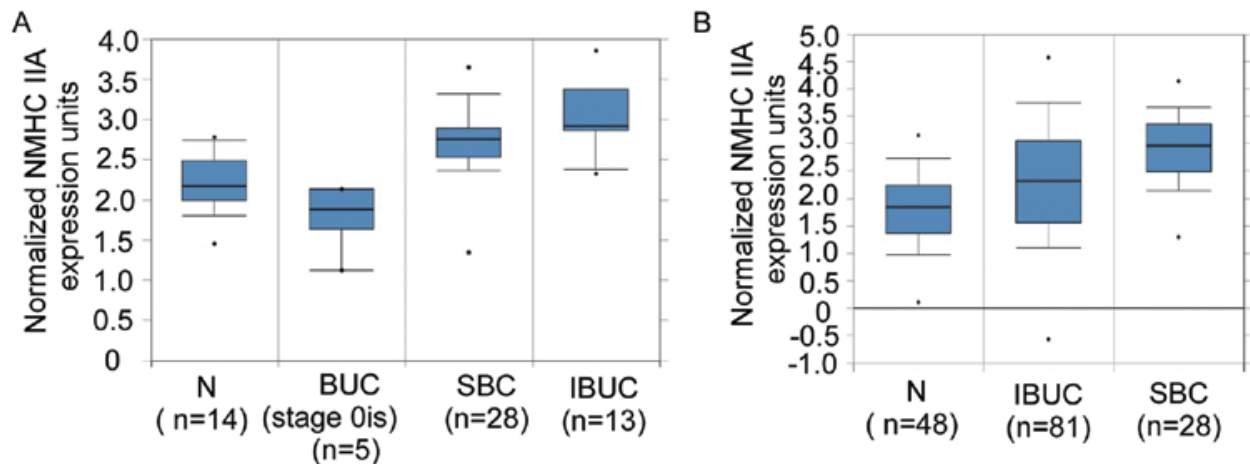

Figure 2. Oncomine boxed plot of NMHC IIA expression levels between human normal and bladder cancer tissues in multiple data sets including those from (A) Dyrskjot et al (16), and (B) Sanchez-Carbayo et al (17). N, normal tissues; BUC Stage 0is, stage 0is bladder urothelial carcinoma; SBC, superficial bladder cancer; IBUC, infiltrating bladder urothelial carcinoma.

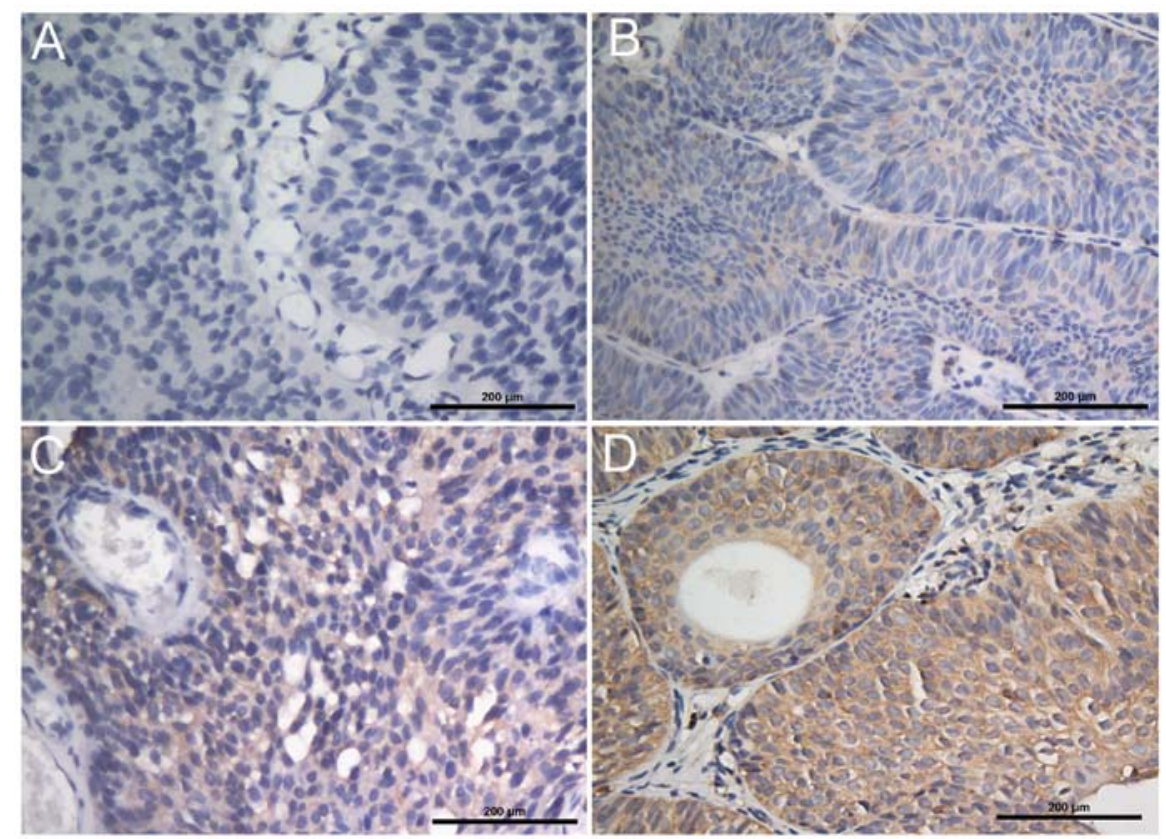

Figure 3. Expression of MHY9 protein by immunohistochemistry assays. MHY9 staining was mainly localized within the cytoplasm and plasma membrane of carcinoma cells. (A) Negative NMHC IIA staining in cancerous cells (x400). (B) Weak MHY9 staining in cancerous cells (x400). (C) Median MHY9 staining in tumor cells (x400). (D) Strong MHY9 staining in tumor nests (x400).

Table III. Univariate and multivariate analysis of potential factors in cystectomy candidates with early-stage bladder cancer.

\begin{tabular}{llcccc}
\hline & & & & \multicolumn{2}{c}{$95 \%$ CI for $\operatorname{Exp}(\mathrm{B})$} \\
\cline { 5 - 6 } Factors & Category & Univariate & Multivariate & Lower & Upper \\
\hline Group & $\mathrm{BS} / \mathrm{RC}$ & 0.406 & 0.422 & 0.298 & 1.660 \\
T-Stage & $\mathrm{T} 1 / \mathrm{T} 2$ & 0.014 & 0.049 & 0.138 & 0.994 \\
Grade & $(\mathrm{G} 1+\mathrm{G} 2) / 3$ & 0.008 & 0.020 & 0.128 & 0.840 \\
Age $($ years $)$ & $\leq 65 />65$ & 0.275 & 0.182 & 0.798 & 3.278 \\
No. & $\leq 3 />3$ & 0.443 & 0.660 & 0.497 & 3.020 \\
Size $(\mathrm{cm})$ & $\leq 3 />3$ & 0.161 & 0.714 & 0.496 & 2.785 \\
Gender & Male/Female & 0.767 & 0.589 & 0.198 & 2.509 \\
NMHC IIA & Low/High & 0.004 & 0.047 & 0.115 & 0.985 \\
\hline
\end{tabular}

BS, bladder-sparing; RC, radical cystectomy. 
A
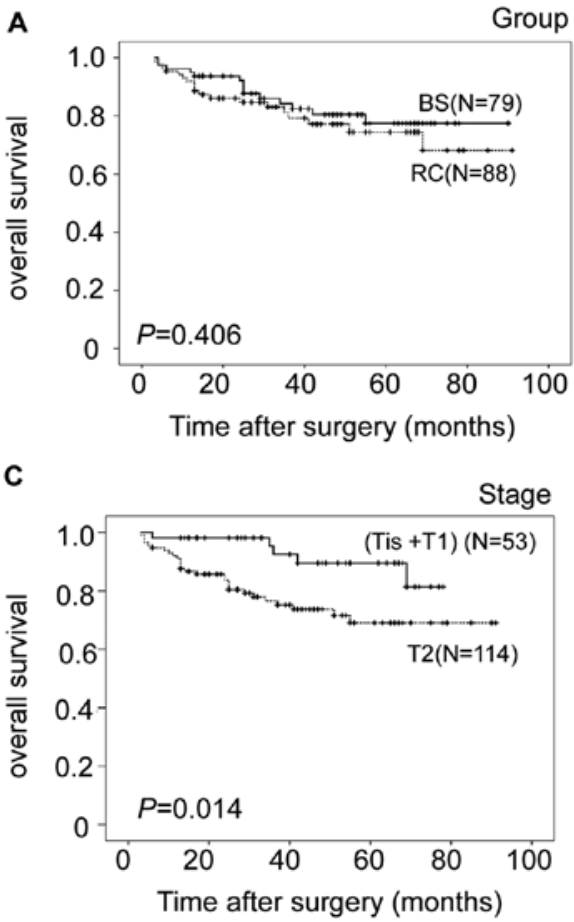

E

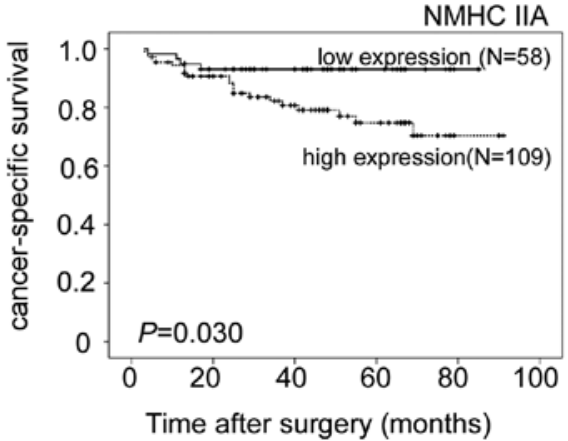

B

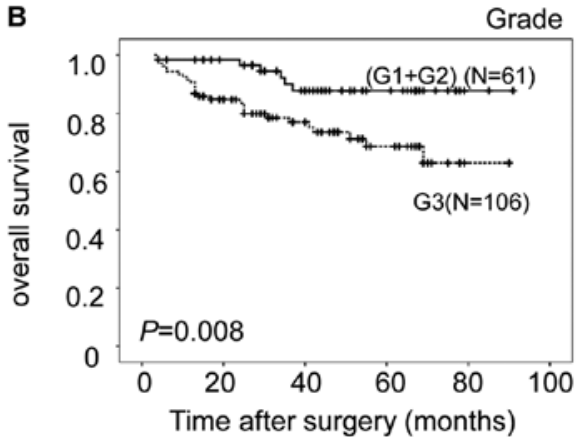

D

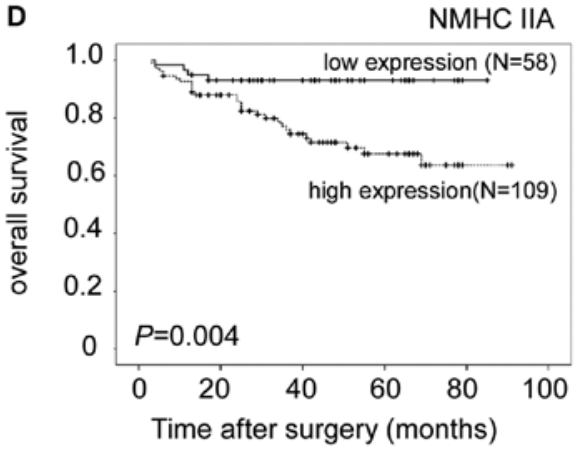

$\mathbf{F}$

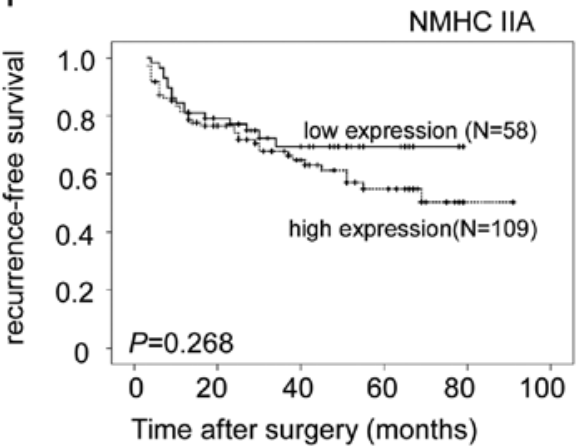

Figure 4. Correlation of clinicopathological variables and NMHC IIA expression with patient survival in bladder cancer. (A-D) Influence of group, grade, T-stage and NMHC IIA expression on the overall survival in bladder cancer. (A) No difference in the overall survival curve was observed in patients with a bladder-sparing approach and those completing radical cystectomy $(\mathrm{P}=0.406)$. (B) The cumulative overall survival exhibited a significant difference based on grade, assessed by Kaplan-Meier curves in bladder cancer tissues $(\mathrm{P}=0.008)$. (C) The survival curves were significantly different according to $\mathrm{T}$-stage $(\mathrm{P}=0.014)$. (D) High NMHC IIA expression was correlated with unfavorable prognosis $(\mathrm{P}=0.004)$. (E) The CSS of the low NMHC IIA expression group was significantly higher than that of the high NMHC IIA expression group (P=0.03). (F) There were no significant differences between the two NMHC IIA expression groups of the RFS $(\mathrm{P}=0.268)$.

istics is shown in Table II. Intense expression of NMHC IIA protein in bladder cancer was not significantly correlated with gender, age, tumor number, tumor size, group or clinical stage ( $P>0.05)$, but was significantly correlated with the histopathological grade and lymph node metastasis $(\mathrm{P}<0.05)$. The high expression of NMHC IIA protein was noted in 54 and $72 \%$ of bladder tumors of histopathological grade $(\mathrm{G} 1+\mathrm{G} 2)$ and $\mathrm{G} 3$, respectively $(\mathrm{P}<0.05)$. In addition, NMHC IIA had increased expression in lymph node metastasis positive tumors compared with lymph node non-metastasis tumors, although the cases of lymph node metastasis positive tumors were very few $(n=7)$.

Univariate and multivariate analyses for prognosis of bladder cancer patients. Univariate and multivariate data analyses were carried out using the Cox proportional hazards regression model to investigate the prognostic value of NMHC IIA expression (Table III and Fig. 4). Grade, clinical T stage and high NMHC IIA expression were the prognostic factors to predict a poor prognosis in univariate analysis $(\mathrm{P}=0.014$, 0.008 , and 0.004 , respectively), however, there was no statistical difference between the overall survival of patients treated with bladder-sparing and those treated with radical cystectomy $(\mathrm{P}=0.406)$ (Table III and Fig. 4A-D). By multivariate analysis of the prognostic factors, we confirmed that high NMHC IIA expression was an independent prognostic factor (95\% confidence interval: $0.115-0.985 ; \mathrm{P}=0.047)$, grade and clinical $\mathrm{T}$ stage were also two independent and significant prognostic factors for overall survival ( $\mathrm{P}=0.02$ and 0.049$)$ (Table III). The survival rate was higher in patients with lower grade and clinical T stage (Fig. 4).

Correlation of clinicopathological variables and NMHC IIA expression with patient survival in bladder cancer. With a median follow-up of 40 months (3-91 months), salvage 

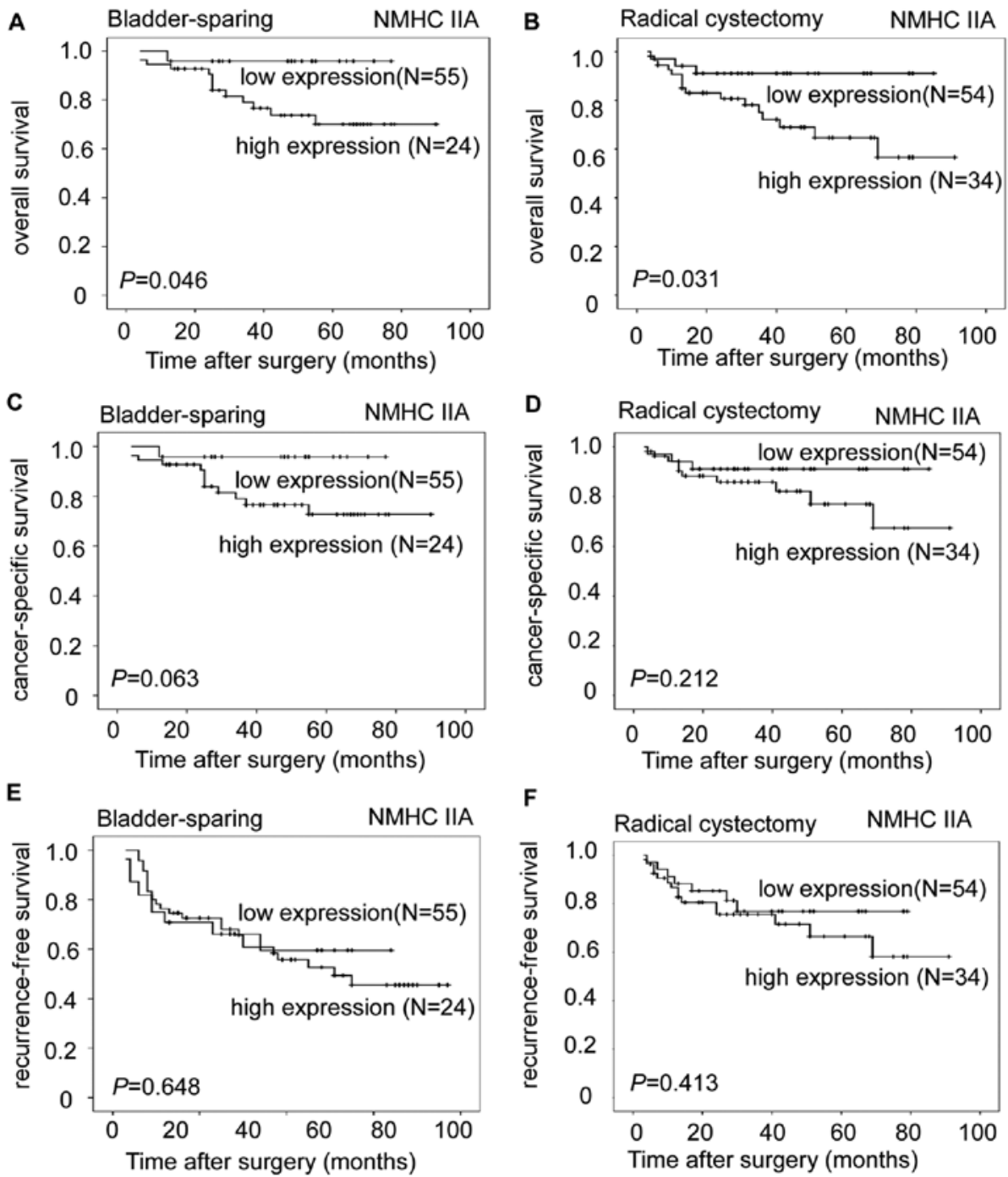

Figure 5. Correlation of NMHC IIA expression with patient survival in bladder cancer treatment with bladder-sparing or radical cystectomy. (A) For bladder cancer patients who completed bladder-sparing treatment, the overall survival of the NMHC IIA protein-high group was significantly lower than that of the NMHC IIA protein-lower group $(\mathrm{P}=0.046)$. (C) Cancer-specific survival of the NMHC IIA protein-high group showed a lower trend compared to that of the NMHC IIA protein-low group ( $\mathrm{P}=0.063)$.(E) Recurrence-free survival of the two groups showed no significant distinction ( $\mathrm{P}=0.648)$. (B) For patients with bladder cancer treated with radical cystectomy, the overall survival of the NMHC IIA protein-low group was significantly higher than that of the NMHC IIA protein-high group $(\mathrm{P}=0.031)$, and (D) there was no statistical difference between the cancer-specific survival of the NMHC IIA protein-low group and that of the NMHC IIA protein-high group $(\mathrm{P}=0.212)$. (F) Recurrence-free survival of the two groups also showed no significant difference ( $\mathrm{P}=0.413)$.

cystectomy was performed in 8 patients and 2 died in 19 and 37 months after initial bladder-sparing treatment. The median time after completing bladder-sparing treatment was 24 months (range 4-37 months). The 3- and 5-year overall survival rates of patients who underwent bladder-sparing treatment, assessed by the Kaplan-Meier method, were 81 and $61 \%$, respectively; those of the patients who completed radical cystectomy were 72 and $54 \%(\mathrm{P}=0.406)$. The association between overall survival and clinical characteristics is shown in Table III and Fig. 4. There was a significantly higher 5-year survival rate in the NMHC IIA protein-low group than in the NMHC IIA protein-high group ( $\mathrm{P}=0.004)$ (Fig. 4D). In addition, we also analyzed the cancer-specific survival (CSS) and recurrence-free survival (RFS) between the two NMHC IIA expression groups in bladder cancer. The CSS of the high NMHC IIA expression group was significantly lower than that of the low NMHC IIA expression group $(\mathrm{P}=0.03)$
(Fig. 4E); there was no significant difference between the two NMHC IIA expression groups of the RFS in bladder cancer $(\mathrm{P}=0.268)$ (Fig. 4F). Furthermore, we divided the patients into two groups according to the treatment in bladder cancer. For patients treated with the bladder-sparing approach, the overall survival of the NMHC IIA protein-low group was significantly higher than that of the NMHC IIA protein-high group $(\mathrm{P}=0.046)$ (Fig. 5A), and the cancer-specific survival of the NMHC IIA protein-low group also showed a higher trend compared to that of the NMHC IIA protein-high group $(\mathrm{P}=0.063)$ (Fig. 5C). Recurrence-free survival of the two groups was not significantly different $(\mathrm{P}=0.648)$ (Fig. 5E). For patients treated with radical cystectomy, the overall survival of the NMHC IIA protein-high group was significantly lower than that of the NMHC IIA protein-low group $(\mathrm{P}=0.031)$ (Fig. 5B), and there was no statistical difference between the cancer-specific survival of the NMHC IIA protein-high 
group and that of the NMHC IIA protein-low group $(\mathrm{P}=0.212)$ (Fig. 5D). Recurrence-free survival of the two groups showed no statistical difference $(\mathrm{P}=0.413)$ (Fig. 5E).

\section{Discussion}

Bladder cancer carries among the highest costs of all types of cancer, from diagnosis until mortality (18). Patients with the same clinicopathological stage of bladder cancer treated with radical cystectomy exhibit considerable variability in survival $(19,20)$. Particularly for cystectomy candidates with early-stage bladder cancer, bladder-sparing treatment is a viable alternative. Therefore, there is an urgent need for new factors that can distinguish between patients with an unfavorable prognosis and those with a better prognosis, and optimize individual management.

This study demonstrated that there was a significant increase of NMHC IIA expression at mRNA levels between bladder cancer cells and the adjacent normal bladder tissue. This result was similar to those of previous studies of other human cancers $(12,14)$. Furthermore, intense expression of NMHC IIA in bladder cancer was correlated with its clinicopathological features including histopathological classification and lymph node metastasis. Our results provide a basic concept that upregulated expression of NMHC IIA in human bladder cancer may be important in the acquisition of a poor prognostic phenotype. Of note, the high expression of NMHC IIA is an independent molecular marker for shortened survival time of patients, who were cystectomy candidates with early-stage bladder cancer, and it might be a helpful criterion to optimize individual therapy management.

In this study, there was a significantly lower 5-year survival rate in the NMHC IIA protein-high group than in the NMHC IIA protein-low group $(\mathrm{P}<0.05)$. The CSS of the low NMHC IIA expression group was significantly higher than that of the high NMHC IIA expression group $(\mathrm{P}=0.03)$, however, there were no significant differences between the two NMHC IIA expression groups of the RFS in bladder cancer $(\mathrm{P}=0.268)$. For patients treated with the bladder-sparing approach or radical cystectomy, the overall survival of the NMHC IIA proteinhigh group was significantly lower than that of the NMHC IIA protein-low group $(\mathrm{P}<0.05)$, and there was no statistical difference between the cancer-specific survival of the NMHC IIA protein-high group and that of the NMHC IIA protein-low group $(\mathrm{P}>0.05)$. Recurrence-free survival of the two groups was also not significantly different $(\mathrm{P}>0.05)$. These results suggest that overexpression of NMHC IIA might not affect the initiation of tumor recurrence, but might induce disease progression after recurrence. Therefore, investigation of the molecular and biological changes associated with NMHC IIA expression in course to carcinogenesis and progression can provide new insight into the pathology of the disease and may provide biological factors as new prognostic markers.

NMHC IIA is a major subunit of the actomyosin cytoskeleton and is generally considered to attribute to the contraction of the cell posterior during migration (21). Previous studies have shown that NMHC IIA plays a key role in tumor cell invasiveness, and the EGF-dependent phosphorylation of the myosin IIA heavy chain has a direct function in mediating motility and chemotaxis in human breast cancer cells
MDA-MB-231 (22). Also, it was reported as a target of SRF, which contributes to invasion and metastasis in breast cancer (23). A recent report suggested that overexpression of let-7f in gastric cancer could inhibit invasion and migration of gastric cancer cells through directly targeting the tumor metastasisassociated gene MYH9/NMHC IIA (24). NMHC IIA has been reported as a decisive protein for cells to invade, indicating that this molecule is a candidate for targeted anti-invasive treatment (25). Our study demonstrated that NMHC IIA had increased expression in lymph node metastasis positive tumors compared with lymph node non-metastasis tumors, although the cases of lymph node metastasis positive tumors were very few. This molecule might reflect the cellular functions of metastasis. Therefore, the exact function of NMHC IIA in bladder cancer, such as metastasis, needs further exploration.

To our knowledge, this is the first report on the overexpression of NMHC IIA in bladder cancer, and it is an independent predictor of overall survival for cystectomy candidates with early-stage bladder cancer. However, as the cystectomy candidates with clinical stage $\mathrm{T} 1$ and $\mathrm{T} 2$ disease represented a specific and small number of the patients with bladder cancer, the correlation between NMHC IIA and bladder cancer requires more detailed investigation. Moreover, the number of patients with lymph node metastasis in this study was few, therefore the findings require further investigation.

\section{Acknowledgements}

This study was supported by grants from the National Natural Science Foundation of China (81072101, 81025014 and 91019015).

\section{References}

1. Jacobs BL, Lee CT and Montie JE: Bladder cancer in 2010: how far have we come? CA Cancer J Clin 60: 244-272, 2010.

2. Gu FL and Liu YL: Changing status of genitourinary cancer in recent 50 years. Chin J Urol 2002: 88-90, 2002.

3. Jemal A, Siegel R, Xu J and Ward E: Cancer statistics, 2010. CA Cancer J Clin 60: 277-300, 2010.

4. Montie JE, Clark PE, Eisenberger MA, et al: Bladder cancer. J Natl Compr Canc Netw 7: 8-39, 2009.

5. Wasco MJ, Daignault S, Zhang Y, et al: Urothelial carcinoma with divergent histologic differentiation (mixed histologic features) predicts the presence of locally advanced bladder cancer when detected at transurethral resection. Urology 70: 69-74, 2007.

6. Zhang M, Tao R, Zhang C and Shen Z: Lymphovascular invasion and the presence of more than three tumors are associated with poor outcomes of muscle-invasive bladder cancer after bladderconserving therapies. Urology 76: 902-907, 2010.

7. Vicente-Manzanares M, Ma X, Adelstein RS and Horwitz AR: Non-muscle myosin II takes centre stage in cell adhesion and migration. Nat Rev Mol Cell Biol 10: 778-790, 2009.

8. Arii J, Goto H, Suenaga T, et al: Non-muscle myosin IIA is a functional entry receptor for herpes simplex virus-1. Nature 467: 859-862, 2010.

9. Simons M, Wang M, McBride OW, et al: Human nonmuscle myosin heavy chains are encoded by two genes located on different chromosomes. Circ Res 69: 530-539, 1991.

10. Burt RA, Joseph JE, Milliken S, Collinge JE and Kile BT: Description of a novel mutation leading to MYH9-related disease. Thromb Res 122: 861-863, 2008.

11. Conti MA and Adelstein RS: Nonmuscle myosin II moves in new directions. J Cell Sci 121: 11-18, 2008

12. Maeda J, Hirano T, Ogiwara A, et al: Proteomic analysis of stage I primary lung adenocarcinoma aimed at individualisation of postoperative therapy. Br J Cancer 98: 596-603, 2008. 
13. Minamiya $Y$, Nakagawa $T$, Saito $H$, et al: Increased expression of myosin light chain kinase mRNA is related to metastasis in non-small cell lung cancer. Tumour Biol 26: 153-157, 2005.

14. Xia ZK, Yuan YC, Yin N, Yin BL, Tan ZP and Hu YR: Nonmuscle myosin IIA is associated with poor prognosis of esophageal squamous cancer. Dis Esophagus: Sep 23, 2011 (Epub ahead of print). doi: 10.1111/j.1442-2050.2011.01261.x.

15. Richards KL,Zhang B, Sun M, et al: Methylation of the candidate biomarker TCF21 is very frequent across a spectrum of earlystage nonsmall cell lung cancers. Cancer 117: 606-617, 2011.

16. Dyrskjøt L, Kruhøffer M, Thykjaer T, et al: Gene expression in the urinary bladder: a common carcinoma in situ gene expression signature exists disregarding histopathological classification. Cancer Res 64: 4040-4048, 2004.

17. Sanchez-Carbayo M, Socci ND, Lozano J, Saint F and CordonCardo C: Defining molecular profiles of poor outcome in patients with invasive bladder cancer using oligonucleotide microarrays. J Clin Oncol 24: 778-789, 2006.

18. Botteman MF, Pashos CL, Redaelli A, Laskin B and Hauser R: The health economics of bladder cancer: a comprehensive review of the published literature. Pharmacoeconomics 21: 1315-1330, 2003.

19. Chen W, Luo JH, Hua WF, et al: Overexpression of EIF-5A2 is an independent predictor of outcome in patients of urothelial carcinoma of the bladder treated with radical cystectomy. Cancer Epidemiol Biomarkers Prev 18: 400-408, 2009.
20. Schrier BP, Hollander MP, van Rhijn BW, Kiemeney LA and Witjes JA: Prognosis of muscle-invasive bladder cancer: difference between primary and progressive tumours and implications for therapy. Eur Urol 45: 292-296, 2004.

21. Ridley AJ, Schwartz MA, Burridge K, et al: Cell migration: integrating signals from front to back. Science 302: 1704-1709, 2003.

22. Dulyaninova NG, House RP, Betapudi V and Bresnick AR: Myosin-IIA heavy-chain phosphorylation regulates the motility of MDA-MB-231 carcinoma cells. Mol Biol Cell 18: 3144-3155, 2007.

23. Medjkane S, Perez-Sanchez C, Gaggioli C, Sahai E and Treisman R: Myocardin-related transcription factors and SRF are required for cytoskeletal dynamics and experimental metastasis. Nat Cell Biol 11: 257-268, 2009.

24. Liang S, He L, Zhao X, et al: MicroRNA let-7f inhibits tumor invasion and metastasis by targeting MYH9 in human gastric cancer. PLoS One 6: e18409, 2011.

25. Derycke L, Stove C, Vercoutter-Edouart AS, et al: The role of non-muscle myosin IIA in aggregation and invasion of human MCF-7 breast cancer cells. Int J Dev Biol 55: 835-840, 2011. 